\title{
Parasites as biological tags for sailfish Istiophorus platypterus from east coast Australian waters
}

\author{
Peter Speare
}

Australian Institute of Marine Science, PMB 3, Townsville MC 4810 , Queensland, Australia

\begin{abstract}
A total of 52 sailfish Istiophorus platypterus from Queensland (Australia) coastal waters were examined for parasites which might provide information on the relationships and movements of fish from different areas. Sailfish from 4 locations between Cape Moreton in southern Queensland and Dunk Island in the north were dissected from 1987 to 1989. Of the 36 parasite taxa which were identified from sailfish, 22 were new host records. Both ordination and classification strategies applied to a combination of 8 long-lived and 8 short-lived parasite taxa indicated different histories of movement for fish from northern and southern locations. The distributions of 2 trypanorhynchs, Callitetrarhynchus gracilis and Otobothrium dipsacum, a copepod, Pennella instructa, and a sanguinicolid, Cardicola grandis, were primarily responsible for discriminating these groups of fish. Analyses of the parasite data from adjacent fishing seasons at Cape Moreton (summer) and Cape Bowling Green (winter), which controlled for apparent interannual variability in parasite abundance, produced clear evidence of discreet subpopulations of sailfish from these locations. Sailfish from the Whitsunday Islands were all mature and, in instances, in spawning condition, whereas fish from other areas were either immature or non-active. Some of the Whitsunday fish had parasite faunas similar to those from northern fishing grounds while others were more similar to Cape Moreton fish. These combined data suggest that fish from the northern and southern grounds may mix in the reef waters of the Whitsundays when mature. The results of analyses undertaken in this study and a concurrent study (Speare 1994, Aust. J mar. Freshwat. Res. 45: 535-549) indicate the utility of parasites to discriminate between billfishes with different histories of movement.
\end{abstract}

KEY WORDS: Biological tags · Sailfish · Parasites

\section{INTRODUCTION}

Beardsley et al. (1974) stated that 'Sailfish [Istiophorus platypterus] are year-round residents over most of their range, however, pronounced seasonal variations in abundance are evident in most areas'. Movements appear to be related to surface seawater temperature. Latitudinal shifts in sailfish abundance off the West African coast apparently follow the $28^{\circ} \mathrm{C}$ isotherm (Ovchinnikov 1966). Similar north-south movements off the coast of Mexico coincide with the seasonal shift in location of the $28^{\circ} \mathrm{C}$ isotherm (Kume \& Joseph 1969). The abundance of sailfish in the Indian Ocean off East Africa significantly increases with the seasonal development of the nutrient rich Somali Current driven by the northeast monsoons when water temperatures reach a maximum of 29 to $30^{\circ} \mathrm{C}$ (Williams 1970). In the NW Pacific, sailfish are more abundant in the warm
Kuroshio Current when they are believed to be spawning (Nakamura 1949).

Voss (1953) believed that sailfish moved into shallow coastal waters (Florida coast, USA) to breed and Jolley (1974) reported a predominance of gravid females southeast of Florida during the northern summer. Williams (1964) concluded that spawning occurred in East African (Kenya) coastal waters through December to February when the above mentioned Somali Current is active. In the Pacific, sailfish apparently spawn throughout the year in warm tropical waters (Yabe 1953). Data from several sources indicate spawning throughout most of the year but with greater activity in the North and South Pacific within their respective summers.

Information which may provide knowledge of the distribution and seasonal abundance of sailfish in the SW Pacific is confounded by the high-seas fisheries 
method of recording catches. No distinction is made between sailfish and shortbilled spearfish Tetrapterus angustirostris. Additionally, these species are not primary target species of the tuna longline fisheries and remain an incidental, but at times considerable, bycatch (Suzuki 1989). Information on the spatial and temporal distribution of sailfish on Australia's east coast is derived solely through the recreational catch via club records and tag returns. Sailfish are seasonally available to game fishermen between the Ribbon reefs, north of Cairns, and Bermagui/Pt. Stephens in central New South Wales. The likelihood of encounter diminishes considerably south of the Queensland border due to low water temperatures and on the Ribbon reefs where fishermen use bait which is too large for sailfish in order to target black marlin Makaira indica.

The major fishing grounds for sailfish (and juvenile black marlin) are the inshore waters off Cairns, Innisfail, Townsville, the Whitsundays and the banks off the northern entrance to Moreton Bay, Brisbane. Cairns, Innisfail and Townsville have a winter fishing season and Brisbane a summer season. In the Whitsundays the season is not so well defined and sailfish may be caught throughout summer and winter. Based on the average seasonal abundance of sailfish, the flow of warm water to southern latitudes in the summer and knowledge from other parts of the world (see above), a hypothesis of latitudinal coastal migration of sailfish might seem reasonable. Information from tag returns, however, contradicts this interpretation.

With 1 exception, tagged sailfish have all been recaptured on the fishing ground where they were originally tagged (Fisheries Research Institute of New South Wales unpubl. data). Excluding fish which have been recaptured shortly after tagging, there is strong evidence for site attachment. A similar situation, with the majority of recaptured fish displaying very localized movements, is evident in the fishery extending through the Gulf of Mexico and Caribbean (Mather et al. 1974).

Parasites have been used to study the recruitment of juveniles to the mature stock, feeding behaviour, the integrity of host populations and host movements. They have been especially valuable in examining host movements (see review by Williams et al. 1992 and appraisal by Lester 1990).

The present study was initiated to further examine the relationships and movements of sailfish along the Queensland coast utilizing information from their parasite fauna. A recent report (Speare 1994) demonstrated the utility of parasites to provide information on the movements of black marlin in Queensland coastal waters by analysing data from several parasites simultaneously. The same approach was used in the analysis of sailfish parasites.

\section{MATERIALS AND METHODS}

A total of 52 sailfish, captured on the nearshore fishing grounds along the Queensland coast between 1987 and 1989, were dissected for parasites. Fish were taken from Dunk Island (DI), Cape Bowling Green (CBG) and the Whitsunday Islands (WHI) in northern Queensland and Cape Moreton (CM) in the south (Fig, 1). Weight (kg), sex and reproductive condition were recorded for each fish examined.

All internal and external metazoan parasites were identified and counted as described in Speare (1994). Summary statistics of mean parasite numbers were compiled for each parasite at each location. The small sample sizes combined with the overdispersed nature of the distributions of most parasites indicated the need for a transformation of the data. The relationships between fish length and parasite numbers were investigated by using logarithmic transformations: $y_{i j}=$ $\log _{10}\left(x_{1 j}+1\right)$ where $x_{i j}$ is the number of the $i$ th parasite in the $j$ th fish and $y_{i j}$ is the corresponding transformed score. The transformed data were used throughout the analyses.

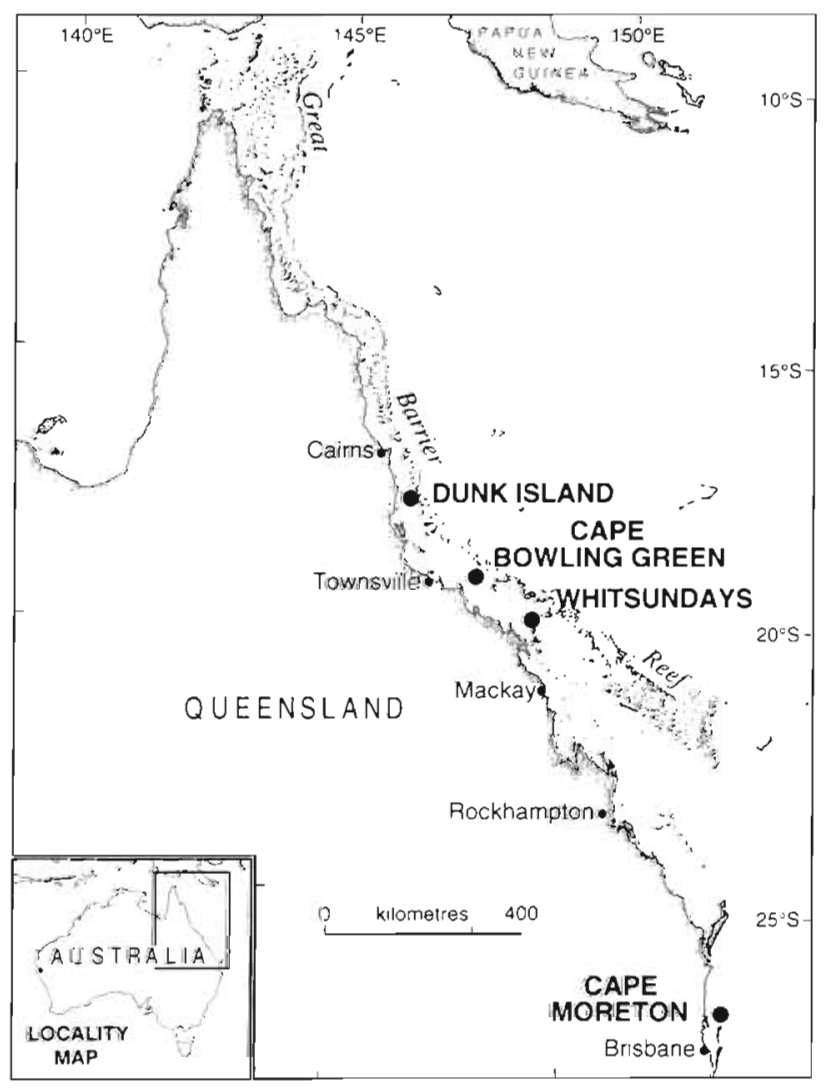

Fig. 1 The 4 sites along the Queensland (Australia) coast from. which sailfish Istiophorus platypterus were obtained for parasitological study 
Parasites from sailfish were considered as permanent or semi-permanent, reflecting their probable longevity on the host. The methodology followed that used by Lester et al. (1985) for skipjack tuna Katsuwonus pelamis. Permanent parasites were those which had a probable life-span of 1 to several years and semipermanent parasites were relatively short lived $(<1$ yr). Those parasites which were rare, ubiquitous or whose measured abundance may have been influenced by this fish's ability to regurgitate were not further considered. Because billfish frequently regurgitate their stomach contents when captured, parasites which were free in the stomach lumen were considered unsuitable as tag parasites. Pathogenicity was also considered in conjunction with life-span in assessing the parasite's potential as a biological tag.

Analyses. Analyses similar to those employed for black marlin (Speare 1994) were undertaken on the sailfish data. PATN (Belbin 1987) was used for classification and ordination analyses. The Bray-Curtis measure (Bray \& Curtis 1957) was utilised to produce similarity matrices. Flexible group average sorting (UPGMA), with a beta value of 0 , was used to produce dendrograms from the association matrices (Clifford \& Stephenson 1975). The relative contribution of each parasite in distinguishing the classified groupings was investigated using Cramer $(C)$ values (Abel et al. 1984). The resulting classifications were then compared with the results from ordination.

Hybrid Multi-Dimensional Scaling (HMDS) (Kruskal \& Wish 1978) was used to produce an ordination of the $n$ fish included in each of the hierarchical classifications. The KYST computer program was accessed via PATN to accomplish these ordinations and the Fortran subroutine SCAT utilised to plot the resultant vectors.

\section{RESULTS}

The weights of the 52 sailfish examined ranged between $4.1 \mathrm{~kg}$ (male) at CBG and $52.2 \mathrm{~kg}$ (female) at WHI (Table 1). Average weights were similar between
DI, CBG and CM but fish were significantly $(p<0.05$, ANOVAj larger at WHI in comparison to these other locations. Only fish from WHI displayed reproductively active gonads. A total of 14 sailfish -10 from CBG and 4 from $C M$ - were recaptured fish that had been previously tagged with standard gamefish tags. Seven fish were recaptured in the same season of tagging Four fish were recaptured 2 to 3 yr later and only 1 fish had moved any measurable distance $(156 \mathrm{~km}$ between Dl and $C B G$ ).

The abundance of each of 36 parasite taxa was recorded from each sailfish. An examination of the relationships between each parasite's abundance $\left[\log _{10}\right.$ (Parasite numbers +1$\left.)\right]$ and fish length indicated positive correlations (equivalent to accumulation of parasites over time) for several taxa (Table 2). There was only slight correlation $\left(\mathrm{r}^{2}=0.07\right)$ between fish length and total parasite burden for sailfish.

\section{Selection of parasites}

\section{Permanent parasites}

Eight parasites were considered to have extended life-spans in the host; these included 4 species of trypanorhynch (Callitetrarhynchus gracilis, Floriceps minacanthus, Otobothrium dipsacum and Otobothrium sp.), 3 didymozoids (Neodidymozoon macrostoma, Nematobothrium sp. A and Makairatrema musculicola) and a copepod (Pennella instructa). Trypanorhynchs are widely recognised as being longlived (e.g. Lubieniecki 1976, Chubb 1980, MacKenzie 1990) as its life-cycle relies on transmission through the food chain to the definitive host. The didymozoids and $P$. instructa are relatively short-lived (Kabata 1958, Lester 1980) but their remains were recognisable in the host tissues well after the death of the parasite, thereby effectively increasing their life-span in the host. (Templeman \& Squires 1960, Lester 1980). Counts of these didymozoids did not tend to increase with fish length, as might be expected with a 'long-lived' species, but it

Table 1 Istiophorus platypterus. The average weight, length and size ranges of sailfish examined for parasites from Queensland coastal waters. LJFL: lower jaw to fork length. DI: Dunk Island; CBG: Cape Bowling Green; WHI: Whitsunday Islands; CM: Cape Moreton

\begin{tabular}{lcrcrcc|}
\hline Location & Year & $\mathrm{n}$ & Avg wt (kg) & Wt range & Avg LJFL (mm) & Length range \\
\hline DI & 1987 & 3 & 31.0 & $18.5-39.5$ & 1877 & $1705-2000$ \\
CBG & 1987 & 11 & 30.5 & $4.1-53.7$ & 1865 & $1020-2370$ \\
CBG & 1988 & 13 & 27.1 & $9.5-38.8$ & 1829 & $1365-2010$ \\
WHI & 1988 & 6 & 39.8 & $27.3-52.2$ & 2108 & $1935-2285$ \\
CM & 1988 & 10 & 29.2 & $20.0-46.0$ & 1966 & $1750-2270$ \\
CM & 1989 & 9 & 31.7 & $20.5-40.8$ & 2009 & $1760-2135$ \\
\hline
\end{tabular}


Table 2. The mean number of each parasite taxa for sailfish Istiophorus platypterus ( $\mathrm{n}=52$ ) from each area and year sampled. $\mathrm{r}$ the correlation coefficient for fish length against $\log _{10}($ Parasite number +1$)$; nd: no data. ${ }^{P}$ Taxon utilised as a permanent parasite;

$s_{\text {taxon }}$ utilised as a semi-permanent parasite. Locality codes as in Table $1 ; 2$ digits following code indicate sampling year

\begin{tabular}{|c|c|c|c|c|c|c|c|}
\hline Parasite & CBG87 & CBG88 & CM88 & CM89 & D187 & WHI88 & r \\
\hline Rhadinorhynchus pristis & 0.1 & 0.0 & 0.0 & 0.0 & 0.0 & 0.0 & 0.00 \\
\hline Bothriocephalus manubriformis ${ }^{s}$ & 12.0 & 3.2 & 104.5 & 23.2 & 38.3 & 15.8 & 0.07 \\
\hline Cestode larva & 0.8 & 0.0 & 0.0 & 0.0 & 0.0 & 0.0 & 0.00 \\
\hline Callitetrarhynchus gracilis ${ }^{P}$ & 0.0 & 0.7 & 0.2 & 0.1 & 8.0 & 1.3 & 0.24 \\
\hline Floriceps minacanthus $^{P}$ & 8.9 & 6.2 & 2.6 & 0.1 & 9.0 & 13.7 & 0.04 \\
\hline Otobothrium dipsacum ${ }^{P}$ & 0.4 & 4.9 & 0.0 & 0.1 & 1.0 & 4.8 & -0.02 \\
\hline Otobothrium sp. ${ }^{P}$ & 0.0 & 0.0 & 0.0 & 0.0 & 0.0 & 125.0 & 0.06 \\
\hline Pterobothrium heterocanthum & 0.0 & 0.1 & 0.0 & 0.0 & 0.0 & 0.2 & 0.00 \\
\hline Gloiopotes longicaudatus & 17.7 & 13.6 & 13.2 & 17.8 & 7.3 & 57.0 & -0.02 \\
\hline Caligus sp. & 11.0 & 44.6 & 148.1 & 128.6 & 4.0 & 80.0 & -0.02 \\
\hline Pennella instructa ${ }^{P}$ & 1.8 & 0.6 & 6.8 & 8.1 & 1.3 & 3.5 & 0.14 \\
\hline Philichthys xiphiae & 0.0 & 0.0 & 0.0 & 0.1 & 0.0 & 0.0 & 0.00 \\
\hline Angionematobothrium jugulare & 0.1 & 0.3 & 0.3 & 0.6 & 1.3 & 0.0 & -0.02 \\
\hline Glomeritrema subcuticola & 0.1 & 0.0 & 0.0 & 0.0 & 0.0 & 0.0 & -0.02 \\
\hline Makairatrema musculicola $^{P}$ & 0.0 & 4.8 & 0.0 & 12.0 & 0.0 & 0.0 & -0.02 \\
\hline Metadidymozoon branchiale $S$ & 14.1 & 50.4 & 149.5 & 135.7 & nd & 14.6 & 0.05 \\
\hline Neodidymozooides microstoma & 0.0 & 0.8 & 0.0 & 0.6 & 0.0 & 0.0 & -0.02 \\
\hline Neodidymozoon macrostoma ${ }^{P}$ & 1.6 & 8.8 & 5.9 & 12.7 & 1.3 & 1.7 & 0.00 \\
\hline Nematobothrium sp. ${ }^{p}$ & 0.8 & 3.2 & 1.9 & 3.3 & 1.7 & 1.2 & -0.04 \\
\hline Nematobothrium sp. $\mathrm{B}^{s}$ & 0.4 & 0.1 & 0.9 & 0.6 & 0.3 & 0.3 & -0.10 \\
\hline Neotorticaecum larva & 0.0 & 0.0 & 0.0 & 0.0 & 0.0 & 1.0 & -0.01 \\
\hline Torticaecum larva & 2.1 & 0.0 & 0.0 & 0.0 & 0.7 & 3.2 & 0.05 \\
\hline Stephanostomum larva & 0.0 & 0.0 & 0.0 & 0.0 & 0.0 & 4.7 & 0.00 \\
\hline Xystretrum papillosum & 0.0 & 0.0 & 0.0 & 0.0 & 0.0 & 3.3 & 0.00 \\
\hline Hirudinella marina & 0.1 & 0.0 & 0.0 & 0.0 & 0.0 & 0.0 & -0.02 \\
\hline Digenean A & 12.5 & 4.5 & 6.9 & 18.1 & 9.0 & 4.0 & -0.02 \\
\hline Digenean $\mathrm{B}$ & 0.0 & 0.2 & 0.3 & 0.9 & 2.7 & 0.0 & -0.02 \\
\hline Digenean $D$ & 4.0 & 0.0 & 0.0 & 0.0 & 0.0 & 0.0 & 0.10 \\
\hline Cardicola grandis ${ }^{5}$ & 13.9 & 17.5 & 0.5 & 12.0 & 6.0 & 4.8 & -0.02 \\
\hline Cypseluritrematoides triangularis & 0.0 & 0.1 & 0.0 & 0.0 & 0.0 & 0.0 & -0.02 \\
\hline Capsaloides istiophoris & 2.6 & 3.5 & 26.8 & 55.2 & n d & 11.8 & 0.04 \\
\hline Capsaloides tetrapterj ${ }^{S}$ & 1.1 & 0.4 & 18.4 & 11.4 & n d & 3.0 & -0.02 \\
\hline Tristomella pricei & 8.7 & 4.0 & 11.9 & 12.3 & 0.3 & 0.7 & 0.03 \\
\hline Camallanus sp. ${ }^{S}$ & 3.0 & 1.8 & 0.2 & 0.0 & 2.0 & 1.7 & -0.12 \\
\hline Nematode larva (intestine) ${ }^{s}$ & 592.1 & 174.5 & 8.6 & 16.2 & 53.0 & 163.7 & 0.05 \\
\hline Hysterothylacium spp. & 5.1 & 31.3 & 1.4 & 3.1 & 3.0 & 28.8 & 0.15 \\
\hline
\end{tabular}

was likely that these parasites would remain with the fish for at least 1 yr. While parasites related to all of the above species have demonstrated pathogenicity, there was no similar evidence amongst the parasites of sailfish.

\section{Semi-permanent parasites}

Eight parasites were considered to have life-spans approaching $1 \mathrm{yr}$ on sailfish. These included the intestinal cestode Bothriocephalus manubriformis, 2 didymozoids (Metadidymozoon branchiale and Nematobothrium sp. B), 2 capsalids (Capsaloides tetrapteri and $C$. istiophori), Cardicola grandis from the heart and ventral aorta, and 2 nematodes (Camallanus sp. and larvae from the intestinal lumen). There is no direct evidence of the life-span of adult cestodes but information on population structure suggests that they are relatively short-lived (Barse 1988). Only live specimens of the didymozoids were recorded from the gills ( $M$. branchiale) and body cavity (Nematobothrium sp. B), which indicated life-spans of $<1$ yr (Self et al. 1963). Monogeneans have a single host life-cycle and are mainly ectoparasitic, which suggests they may be more sensitive to unfavourable changes in the environment. Life-spans appear to vary from less than 1 yr to over 2 yr (Chubb 1977). Llewellyn $(1962,1964)$ suggested that the gill parasites Gastrocotyle trachuri and Pseudaxine trachuri on Trachurus trachurus normally live no longer than 1 yr

The life-cycle of sanguinicolids, with a molluscan intermediate host and several larval stages, coupled with the generally short-lived feature of digeneans suggest Cardicola grandis as a semi-permanent parasite. Larvae and adult nematodes which are free in the 
lumen of the intestine or stomach generally have relatively short lives in marine fish (Margolis 1970). Nematodes have been extensively and successfully utilized to discriminate between groups of fish and consequently Camallanus sp. (Spirurida: Camallanidae) and larval nematodes from the intestinal lumen were utilised as semi-permanent parasites.

Parasites not utilised in the analyses included those which were rare (e.g. Rhadinorhynchus pristis and Philichthys xiphiae), may have been overlooked in dissection (Angionematobothrium jugulare), occurred in the stomach lumen (hemiurids and larval didymozoids) or were otherwise very short-lived on the host (e.g. Caligus sp. and Gloiopotes longicaudatus).

\section{Relationships amongst fish}

Permanent parasites

Classification of all sailfish irrespective of sampling season identified mixed groups of fish (Fig. 2A). The most dissimilar groups (groups 5 to 7 ) included fish with very few long-lived parasites and the smallest fish dissected (group 6, a $4.1 \mathrm{~kg}$ fish). Of the 6 fish from WHI, 3 were recognised by the large numbers of Otobothrium sp. which were absent from all other fish and absent or in low numbers in the other WHI sailfish. Two trypanorhynchs [Otobothrium sp. (Cramer value, $C=0.95)$ and Callitetrarhynchus gracilis $(C=0.71)\}$ and Nematobothrium sp. A $(C=0.46)$ had the greatest influence in distinguishing these groups.

HMDS did not, in general, corroborate the similarities highlighted by classification. The most dissimilar groups revealed by classification were readily identified in the 2-dimensional ordination, but there was considerable overlap in groups 1,2 and 3. A line drawn by eye through the array separated, to a very large extent, fish from $\mathrm{CM}$ and those north of $\mathrm{CM}$.

\section{Semi-permanent parasites}

A similar classification was obtained using semipermanent parasites but with more distinct groupings than that based on permanent parasites (Fig. 2B). Two major groups were recognised (groups 1 and 2), each a composite of fish from several locations and years, based principally on the distributions of Metadidymozoon branchiale $(C=0.86)$, Bothriocephalus manubriformis $(C=0.77)$, Capsaloides tetrapteri $(C=0.63)$ and Cardicola grandis $(C=0.59)$. A line drawn through the ordination array separated the majority of $\mathrm{CM}$ fish from fish in areas to the north. WHI sailfish displayed similarities to fish from both CM and CBG.
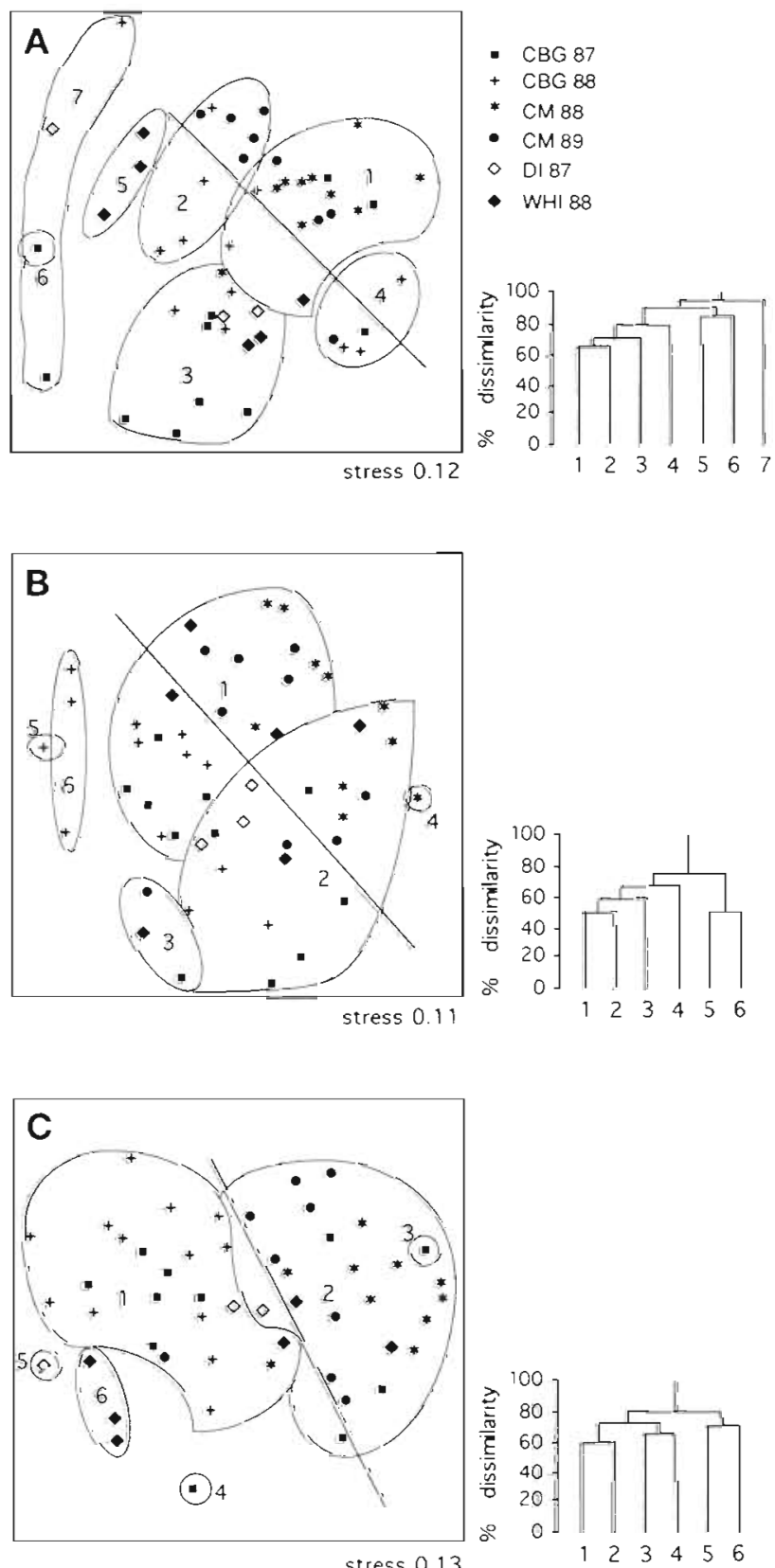

stress 0.13

Fig. 2. Istiophorus platypterus. Results of ordination and classification of sailfish from all localities and years sampled based on their (A) permanent, (B) semi-permanent and (C) combined permanent and semi-permanent parasites. Curves enclose the major groups defined by classification for a direct comparison with the results of ordination. The line drawn by eye through the array tends to separate fish from north and south. Locality codes in text and Table 1

Permanent and semi-permanent parasites

In contrast to the results based on the distributions of permanent or semi-permanent parasites, the combination of these parasites produced a classification 
paralleling the groups revealed through ordination (Fig. 2C). With few exceptions, CM fish were distinct from those to the north. Two WHI salfish were more closely associated with $C M$ fish whereas the DI and remaining WHI fish were more similar to $\mathrm{CBG}$ fish. Two species of trypanorhynch [Callitetrarhynchus gracilis $(C=0.95)$ and Otobothrium dipsacum $(C=0.89)]$, Pennella instructa $(C=0.72)$ and Cardicola grandis $(C=0.71)$ discriminated these groups of fish.

\section{Interannual variability}

Mean abundance figures (Table 2) indicated annual shifts in the levels of infection by parasite taxa of fish from $\mathrm{CBG}$ and $\mathrm{CM}$. This may be attributable to interannual variability. This was particularly evident for species such as Makairatrema musculicola, which was absent from all fish from CBG in 1987 and CM in 1988, but was present in fish at these locations the following year. Also, for example, Neodidymozoon macrostoma mean infection levels went from 1.6 to 8.8 at CBG and 5.9 to 12.7 at $\mathrm{CM}$ over the $1 \mathrm{yr}$ period. To minimise any effects of interannual variability in exposure to infections, the analyses were re-run with fish from CBG in 1987 ( $\mathrm{n}=11)$ and $C M$ in $1988(\mathrm{n}=10)$. Fish in these samples had similar mean weights (Table 1).

\section{Permanent parasites}

Two major groups of fish were defined predominantly on the basis of the distributions of Pennella instructa $(C=0.91)$ and Floriceps minacanthus $(C=$ 0.82). Two CBG sailfish ( $\mathrm{C}$ and $\mathrm{d}$ in Fig. $3 \mathrm{~A}$ ) were more closely associated with $\mathrm{CM}$ fish, but otherwise fish segregated on the basis of locality (Fig. 3A). Groups 2 and 4 were represented by single fish from $C B G$ which were the smallest fish with very few (b) or no (a) parasites recognised as permanent.

\section{Semi-permanent parasites}

The semi-permanent parasites of $\mathrm{CBG}$ sailfish distinguished them from $\mathrm{CM}$ fish (Fig. 3B). Intestina] nematode larva $(C=0.76)$, Camallanus sp. $(C=0.70)$, Cardicola grandis $(C=0.64)$ and Bothriocephalus manubriformis $(C=0.63)$ distributions delineated these groups of fish. A similar pattern was achieved from ordination.

\section{Permanent and semi-permanent parasites}

A combination of the permanent and semi-permanent parasites produced 3 groups of fish, 1 of which was a single fish, and the smallest fish (a), from CBG
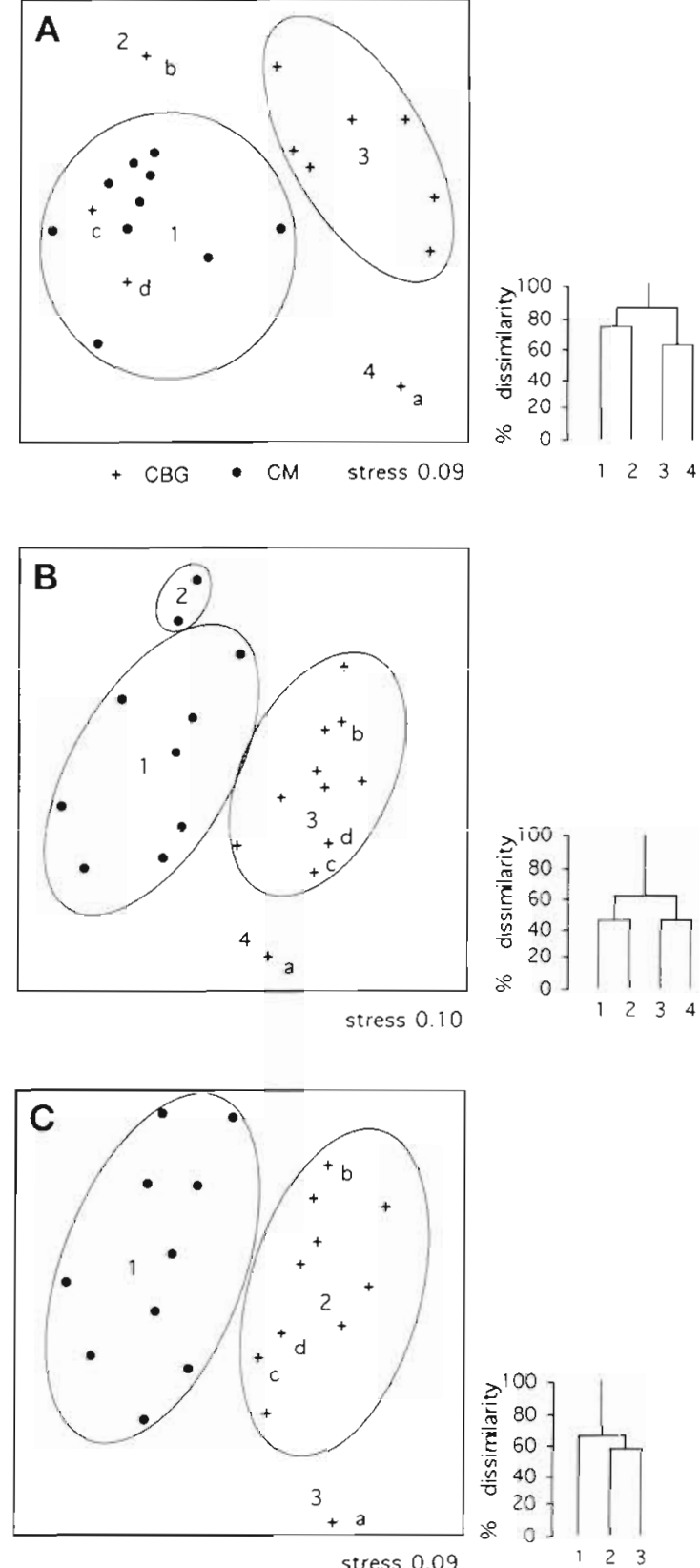

Fig. 3. Istiophorus platypterus. Results of ordination and classification of sailfish from Cape Bowling Green (CBG) in 1987 and Cape Moreton (CM) in 1988 based on their (A) permanent, (B) semi-permanent and (C) combined permanent and semi-permanent parasites. The curves enclose the major groups defined by classification for a direct comparison. with the results of ordination. a: smallest fish with no parasites recognized as permanent; $b$ : second-smallest fish with few parasites recognized as permanent; $c$ and $d: 2$ fish more closely associated with CM fish

(Fig. 3C). It was more closely associated with all other fish from CBG which were distinct from all CM sailfish. The distribution of Floriceps minacanthus $(C=0.95)$ 
was predominant in classifying the fish groups as well as Bothriocephalus manubriformis $(C=0.33)$ and Pennella instructa $(C=0.26)$. The classification was reflected in the results of ordination.

\section{DISCUSSION}

The list of parasites recorded from sailfish can be compared to other species of pelagic piscivorous fish for which intensive sampling has been undertaken (e.g. Hogans et al. 1983, Lester et al. 1985, Speare 1994). Some parasite taxa were particularly well represented, such as trypanorhynchs and didymozoids which have provided valuable insights on fish stock associations and movements (e.g. Mackenzie 1990, Jones 1991).

Very few studies of parasites as biological tags have utilised groups of parasites simultaneously to investigate fish populations. Arthur \& Arai (1980) used multicategory (3 parasites) linear discriminate analysis and $k$ nearest neighbour classification to examine the relationships between geographical stocks of Clupea harengus pallasi in British Columbia and Alaskan waters. Canonical multivariate analysis was used by Lester et al. (1985) to examine the parasite data from skipjack tuna Katsuwonas pelamis and again in a study of orange roughy Hoplostethus atlanticus (Lester et al. 1988). In this study of sailfish, analysis of several parasites simultaneously was the only suitable strategy to counter the effects of small sample size, biases related to the overdispersed nature of individual parasite distributions and annual variability of infections (Lester 1990).

The most consistent feature of the HMDS analyses undertaken on sailfish was the segregation of the greater majority of fish between northern (CBG, DI and WHI) and southern (CM) locations. At CBG and $C M$, where fish were sampled over 2 yr, some parasites displayed what might be interpreted as high interannual variability in mean abundance, e.g. Makairatrema musculicola and Cardicola grandis at CM. A combination of relatively small sample sizes and the overdispersed nature of many of the parasites' distribution in the host could, however, also account for this perceived interannual variation.

The parasite faunas compared between adjacent seasons at CBG and CM clearly identified isolated groups of fish at these localities. These findings do not support a theory of latitudinal migration of sailfish between fishing grounds along the Queensland coast, but they are in agreement with results from artificial tagging which show no movement of fish between north and south (Pepperell 1984, 1985).

A few fish displayed little affinity with the major fish groups due to unusually low and/or high levels of infection by some parasites. A $4.1 \mathrm{~kg}$ fish (marked 'a' in Fig. 3) was distinct from all other fish; because of its young age, it had limited exposure to infection. The other outliers each had combinations of the relevant parasites whose intensities were well above or below mean levels.

Fish from the WHI were more closely associated with CBG and DI sailfish in their permanent parasites but there was evidence of a relationship with CM sailfish in respect to their semi-permanent parasite fauna. Only sailfish from the WHI exhibited reproductive activity in the summer months (author's unpubl. data) when spawning is at a peak (Voss 1953, Williams 1964). The fish at WHI were considerably larger than the average fish on the other fishing grounds and it is possible that the larger mature fish along the coast move into the reef waters for summer spawning. If so, then the WHI fish may represent a reproductive link between fish in areas to the north and south.

These results contrast with those from a similar study of black marlin parasites (Speare 1994). Juvenile black marlin, which co-occur with sailfish in nearshore waters, remain isolated from the mature fish which are rarely found in shallow coastal waters. They recruit to the adult stock with the onset of sexual maturity.

Acknowledgements. I am indebted to Mike Cappo who assisted me in the field and with dissections. Also to fishermen who provided the bulk of material from their fishing exploits. I thank Dave Williams for his support of this work and many helpful thoughts towards its completion.

\section{LITERATURE CITED}

Abel, D. J., Williams, W. T., Williams, D. McB. (1984). A fast classificatory algorithm for large problems and the BrayCurtis measure. J. exp. mar. Biol. Ecol. 89: 237-245

Arthur, J. R., Arai, H. P. (1980). Studies on the parasites of pacific herring (Clupea harengus pallasi Valenciennes): a preliminary evaluation of parasites as indicators of geographical origin for spawning herring. Can. J. Zool. 58: $521-527$

Barse, A. (1988). A contribution to the biology of white marlin, Tetrapterus albidus, off the Delaware and Maryland coast (U.S.A.) with special emphasis on feeding ecology and helminth parasites. M.Sc thesis, Univ. of Maryland, Baltimore

Beardsley, G. L. Jr, Merrett, N. R., Richards, W. J. (1974). Synopsis of the biology of the sailfish, Istiophorus platypterus (Shaw and Nodder, 1791). In: Shomura, R. S., Williams, F. (eds.) Proc. int. Billfish Symp., Kailua-Kona, Hawaii, 9-12 August 1972. U.S. Dept Commerce, NOAA Tech. Rep. NMFS SSRF-675(2): 95-116

Belbin, L. (1987). PATN, pattern analysis package, Reference manual, Parts 1 \& 2. Div. Wildlife Rangelands Research, CSIRO

Bray, J. R., Curtis, J T (1957). An ordination of the upland forest communities of southern Wisconsin. Ecol. Monogr. 27: $325-349$ 
Chubb, J. C. (1977). Seasonal occurrence of helminths in freshwater fishes, Part I. Monogenea. Adv. Parasitol. 15: $133-199$

Chubb, J. C. (1980). Seasonal occurrence of helminths in freshwater fishes, Part III. Larval cestoda and nematoda. Adv. Parasitol. 18: 1-120

Clifford, H. T., Stephenson, W. (1975). An introduction to numerical classification. Academic Press, New York

Hogans, W. E., Brattley, J., Uhazy, L. H. (1983). Helminth parasites of swordfish (Xiphias gladius L.) from the Northwest Atlantic Ocean. J. Parasitol. 69(6): 1178-1179

Jolley, J. W. Jr (1974). On the biology of Florida east coast Atlantic sailfish (Istiophorus platypterus). U.S. Dept Commerce, NOAA Tech. Rep. NMFS SSRF-675: 81-88

Jones, J. B. (1991). Movements of albacore tuna (Thunnus alalungal in the South Pacific: evidence from parasites. Mar. Biol. 111: 1-9

Kabata, Z. (1958). Lernaeocera obtusa n. sp., its biology and its effects on the haddock. Mar. Res. 1958 (3): 1-26

Kruskal, J. B., Wish, M. (1978). Multidimensional scaling Sage Publications, Beverly Hills

Kume, S., Joseph, j. (1969). The Japanese longiine tishery for tunas and billfishes in the eastern Pacific Ocean east of $130^{\circ} \mathrm{W}, 1964-66$. Inter-Am. Trop. Tuna Comm. 13: $277-418$

Lester, R. J. G. (1980). Host-parasite relations in some didymozoid tremalodes. J. Parasitol. 66(3): 527-531

Lester, R. J. G. (1990). Reappraisal of the use of parasites for fish stock identification. Aust. J mar. Freshwat. Res. 41 $855-864$

Lester, R. J. G., Barnes, A., Habib, G. (1985). Parasites of skipjack tuna Katsuwonus pelamis: fishery implications. Fish. Bull. U.S. 83: 343-356

Lester, R. J. G., Sewell, K. B., Barnes, A., Evans, K. (1988) Stock discrimination of orange roughy, Hoplostethus atlanticus, by parasite analysis. Mar. Biol. 99: 137-143

Llewellyn, J. (1962). The life histories and population dynamics of monogenean gill parasites of Trachurus. J. mar. biol. Ass. U.K. 42: 587-600

Llewellyn, J. (1964). The effects of the host and its habits on the morphology and life-cycle of a monogenean parasite. In: Ergens, R., Rysavy, B. (eds.) Parasitic worms and aquatic conditions. Czechoslovak. Acad. Sci, Prague, p. $147-152$

Lubieniecki, B. (1976). Aspects of the biology of Grillotia erinaceus (van Beneden, 1858) (Cestoda: Trypanorhyncha) in haddock, Melanogrammus aeglefinus (L.). J. Fish. Biol. 8: 431-439

MacKenzie, K. (1990). Cestode parasites as biological tags for mackerel (Scomber scombrus L.) in the Northeast Atlantic. J. Cons. int. Explor Mer 46: 155-166

This article was submitted to the editor
Margolis, L. (1970). Nematode diseases of marine fishes. In: Snieszko, S. F. (ed.) A symposium on diseases of fishes and shellfishes. Am. Fish. Soc. Spec. Publs No. 5, p. 190-208

Mather, F. J. III, Tabb, D. C., Mason, J. M. Jr, Clark, H. L. (1974). Results of sailfish tagging in the western North Atlantic Ocean. NOAA Tech. Rep., NMFS SSRF-675: $194-210$

Nakamura, H. (1949). The tunas and their fisheries. (Translated by Van Campen, W. G., 1952). U.S. Fish Wildl. Serv., Spec. Rep. Fish. 82: 1-115

Ovchinnikov, V. V. (1966). The effect of oceanographic conditions on distribution of the sailfish, Istiophorus americanus, off the West African coast. Oceanology 6:566-567

Pepperell, J. G. (1984). Gamefish tagging, 1982-1983. N.S.W. Dept Agricult. Fish. Res. Inst., Sydney

Pepperell, J. G. (1985). Gamefish tagging, 1983-1984. N.S.W. Dept Agricult., Fish. Res. Inst., Sydney

Self, J. T., Peters, L. E., Davis, C. E. (1963). The egg, miricidium, and adult of Nematobothrium texomense (Trematoda: Digenea). J. Parasitol. 49: 731-736

Speare, P. (1994). Relationships amongst black marlin, Makaira inaica, in Easiern Ausiralian coastal wäters, inferred from parasites. Aust. J mar. Freshwat. Res. 45: $535-549$

Suzuki, S. (1989). Catch and fishing effort relationships for striped marlin, blue marlin, and black marlin in the Pacific Ocean, 1952 to 1985. In: Stroud, R. T. (ed.) Proc. 2nd int. Billfish Symp., Kailua-Kona, Hawaii, 1-5 August, 1988, Part 1. National Coalition for Marine Conservation, Savannah, GA, p. 165-177

Templeman, W., Squires, H. J. (1960). Incidence and distribution of infestation by Sphyrion lumpi (Kroyer) on the redfish, Sebastes marinus (L.), of the western North Atlantic. J. Fish. Res. Bd Can. 17: 5-31

Williams, F. (1964). The scombroid fishes of East Africa, Proc. Symp. Scombroid Fishes, Part 1 Mar. Biol. Ass. India, Mandapam Camp, p. 107-164

Williams, F. (1970). The sport fishery for sailfish at Malinda, Kenya, 1958-1968, with some biological notes. Bull. mar. Sci. 20: 830-852

Williams, H. H., MacKenzie, K., McCarthy, A. M. (1992). Parasites as biological indicators of the population biology, migrations, diet, and phylogenetics of fish. Rev. Fish Biol. Fish. 2: $144-176$

Voss, G. L. (1953). A contribution to the life history and biology of the sailfish, Istiophorus americanus Cuv. and Val., in Florida waters. Bull. mar. Sci. Gulf Caribb. 3: 206-240

Yabe, H. (1953). On the larvae of sailfish, Istiophorus orientalis, collected in the South-western Sea of Japan. Contrib. Nankai Reg. Fish. Res. Lab. 6: 1-10 (in Japanese with English synopsis)

Manuscript first received: May 18, 1993

Revised version accepted: November 30, 1994 